PontIFícIa UNIVERSIDADE CATÓLICA dO RIO DE JANEIRO

\title{
ESTRATÉGIAS DO PROGRAMA DE VOLUNTARIADO DA SIEMENS BRASIL
}

\author{
Daniel Sol Cacique Zarur
}

Trabalho de Conclusão de CuRso

Centro de ciências socials - CCS

DEPARTAMENTO DE ADMINISTRAÇÃO

Graduação em Administração de Empresas 

หr̆

Daniel Sol Cacique Zarur

Estratégias do Programa de Voluntariado da Siemens

Brasil

Trabalho de Conclusão de Curso

Trabalho de Conclusão de Curso, apresentado ao programa de graduação em Administração da PUCRio como requisito parcial para a obtenção do titulo de graduação em Administração.

Orientador(a) : Edmundo Eutrópio

Rio de Janeiro, 9 de Junho de 2017 


\section{Resumo}

Zarur, Daniel S. Estratégias do programa de voluntariado da Siemens Brasil. Rio de Janeiro, 2017. 43 p. Trabalho de Conclusão de Curso Departamento de Administração. Pontifícia Universidade Católica do Rio de Janeiro. Souza, Edmundo E. C. de (Orientador)

Este trabalho tem o objetivo de estudar o programa de voluntariado empresarial da Siemens. Buscou-se observar e analisar quais estratégias foram adotadas pela empresa para se tornar referência em cidadania coorporativa. A partir de pesquisa bibliográfica e coleta de dados secundários foram realizadas posteriormente entrevistas com o representante da empresa no voluntariado no Rio de Janeiro. O resultado deste estudo pode auxiliar outras empresas a desenvolverem práticas de voluntariado que gerem benefícios para a sociedade.

\section{Palavras- chave}

voluntariado empresarial; cidadania coorporativa; responsabilidade empresarial

\section{Abstract}

Zarur, Daniel S. Strategies of Siemems' corporate volunteer program. Rio de Janeiro,2017. 43 p. Trabalho de Conclusão de Curso - Departamento de Administração. Pontifícia Universidade Católica do Rio de Janeiro. Souza, Edmundo E. C. de (Orientador)

This research has the goal to study the Siemems' corporate volunteer program. It seeks to observe and analize which strategies were adopted by the company to change into a reference about corporative citizenship. From the bibliography research and data collect, the study also uses an interview with the company representative of volunteering in Rio. The result of this study can help other companies to develop volunteering techniques which may bring benefits to the society.

\section{Key-words}

corporate volunteer ; corporate citizenship; corporate responsibility 


\section{Sumário}

1 Introdução

2 Contexto e Realidade Investigada $\quad 7$

2.1. Voluntariado Empresarial $\quad 7$

2.2. Siemens 9

2.3. Fundação Siemens 11

3 Diagnóstico da situação problema e oportunidade 12

3.1. Reflexão dos motivos para se implantar o programa de voluntariado empresarial.

3.2. Comitê 14

$\begin{array}{ll}\text { 3.3. Recursos } & 15\end{array}$

$\begin{array}{ll}3.4 \text { Difusão } & 17\end{array}$

3.5 Necessidades da comunidade 18

$\begin{array}{ll}3.6 \text { Projeto do programa voluntário } & 19\end{array}$

3.7 Gerenciamento dos projetos do programa de voluntariado 20

3.8 Valorização, reconhecimento e comunicação. 21

$\begin{array}{ll}3.9 \text { Parcerias } & 23\end{array}$

3.10 Exemplos de projetos desenvolvidos após a implantação do $\begin{array}{ll}\text { programa } & 25\end{array}$

4 Análise da situação e proposta de solução 27

4.1. Decisão de implantação e definição da temática 27

4.2. Estrutura 29

4.3. Recursos 31

4.4. Projetos 31

4.5. Voluntários 33

4.6. Instituição Siemens e parceiras 35

4.7. Comunicação 36

$\begin{array}{ll}4.8 \text { Reconhecimento } & 38\end{array}$ 


\section{Lista de figuras}

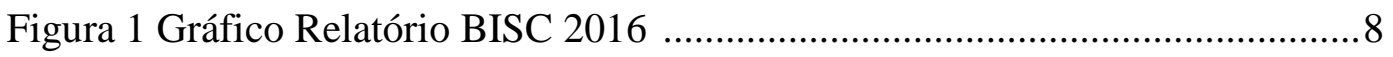

Figura 2 Gráfico Relatório BISC 2016 ……....................................................29

Figura 3 Organograma departamento sustentável ..............................................30

Figura 4 Pirâmide das Necessidades Humanas Básicas MASLOW ........................34

Figura 5 Meios de divulgação de atuação social .................................................38

\section{Lista de Tabelas}

Tabela1 Relatório BISC 2016, Comunitas .28 


\section{Introdução}

As organizações, que são parte integrante da sociedade, há algum tempo vêem atuando de maneira expressiva no voluntariado empresarial. A contribuição deste setor tem sido relevante em toda a sociedade. Atualmente há diversas instituições que se dedicam ao estudo e a fomentar a prática do voluntariado. Tais organizações defendem que é possível obter vantagem competitiva e ao mesmo tempo contribuir para o desenvolvimento social.

Como parte de sua estratégia de cidadania corporativa, a Siemens Brasil desenvolveu um programa de voluntariado e buscou o engajamento de seus funcionários. Empenhada em construir uma sociedade com igual oportunidade para todos, suas ações são voltadas principalmente para área de educação .

O presente artigo tem como objetivo analisar as estratégias utilizadas por uma grande empresa, no caso a Siemens Brasil, em seu programa de voluntariado empresarial. Este projeto foi adotado pela empresa desde 2012 em seus 13 escritórios regionais. A relevância da análise deste caso específico é poder auxiliar outras empresas no desenvolvimento da prática do voluntariado, o que gera benefícios para toda a sociedade. Além de também servir de referência para o fortalecimento e o desenvolvimento de políticas públicas e outros programas e ações que tenham como objetivo o bem-estar social.

O presente estudo está organizado em cinco seções, sendo esta introdução a primeira delas; na segunda seção o contexto e a realidade investigada são abordados; na terceira, descreve-se as etapas do processo de implantação do programa de voluntariado e como o programa funciona atualmente; na quarta, analisa-se as estratégias utilizadas pela Siemens, e na quinta são apresentadas a conclusão e a contribuição deste artigo em seu âmbito de atuação. 


\section{Contexto e Realidade Investigada}

\subsection{Voluntariado Empresarial}

É perceptível, no mundo contemporâneo, a volatilidade do status quo em que estamos inseridos. As mudanças contínuas no âmbito social, econômico e político moldam a forma como a sociedade e as empresas se relacionam. De maneira lógica, para que as organizações permaneçam sólidas dentro do mercado é preciso que elas se adaptem às novas expectativas e preocupações, sejam do próprio mercado, de outras instituições ou da comunidade.

Diante desse pensamento e frente a tais mudanças há uma ideia se defasando: a que o bem-estar social é uma responsabilidade apenas do Estado. Para substituí-lo, surge, então, a nova concepção de que essa incumbência pode e deve ser compartilhada entre as demais esferas da sociedade. Mas, qual o motivo para essa substituição?

Podemos afirmar que estamos vivendo um progresso nos níveis de conscientização. Isso se dá na medida em que o debate em escala mundial de temas como desenvolvimento sustentável e responsabilidade social aumenta e ajuda a expor a importância dessas causas, promovendo o estudo de suas práticas.

O conceito de responsabilidade social empresarial vive essa realidade. As empresas passaram a se conscientizar mais da sua parte no desenvolvimento da sociedade. A "alma do negócio" não é apenas a busca pelo lucro, mas importa também contribuir socialmente, baseando-se em melhorias de aspectos fundamentais como meio ambiente, educação, moradia e saúde.

O relatório de Benchmarking do Investimento Social Corporativo (BISC), é um instrumento para acompanhar os investimentos sociais realizados no Brasil. Criado pela Comunitas, uma organização que busca estimular empresas a participarem no desenvolvimento social e econômico. 
No gráfico abaixo, podemos acompanhar o volume financeiro do investimento social realizado pelas empresas que participaram das pesquisas no relatório BISC ao longo dos anos de 2007 a 2015.

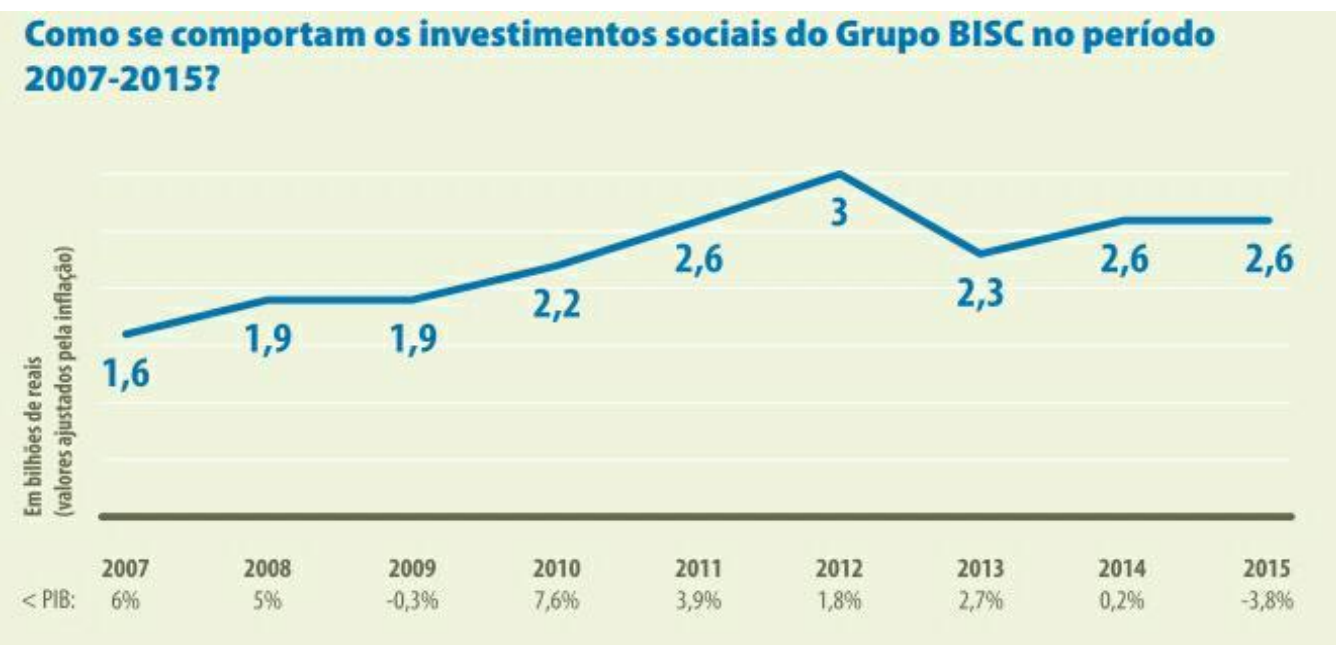

Figura 1 Grafico Relatório BISC 2016.09

Tais contribuições acontecem por meio de ações e projetos promovidos pelas corporações praticantes do voluntariado empresarial. Segundo Galiano e Medeiros Filho (Ethos 2003, p.31):

“o voluntariado empresarial designa os programas de apoio à ação voluntária dentro das empresas. Trata-se de organizar a disposição para o trabalho voluntário entre empregados e dirigentes, às vezes incorporando seus familiares, ex-empregados que se aposentaram, fornecedores, distribuidores, prestadores de serviços, clientes, parceiros de negócios.(...) Mobiliza as pessoas de maneira espontânea, não compulsória, estimulando o envolvimento em causas de interesse colectivo. Educa para a cidadania, revelando o que cada um tem de melhor."

No processo de implantação do programa de voluntariado empresarial, as escolhas de sua operacionalização e estratégias deverão ser delineadas de acordo com os resultados esperados pela organização. A maioria das empresas que 
realizam voluntariado possuem um setor encarregado por elaborar sua iniciativas sociais e oferecer suporte a suas ações.

De acordo com a CBVE (2013, p.11), “O processo de concepção de um programa de voluntariado empresarial pressupõe um conjunto de escolhas relacionadas à sua forma de ocorrência: presencial ou à distância; pontual ou sistemática; em projetos próprios, em organizações sociais ou espaços públicos”.

Fischer e Falconer (1999), na pesquisa Estratégias de empresas no Brasil: Atuação social e voluntariado, difundem que as ações podem variar de apoio informal para que as pessoas se dediquem fora do horário de trabalho até a criação de formais, nos quais funcionários são convidados a realizar atividades durante o horário de trabalho, além da utilização de outros recursos organizacionais.

\subsection{Siemens}

Fundada em 1847, a Siemens é uma das maiores produtoras mundiais de tecnologias de economia de recursos em termos energéticos. É a fornecedora líder de sistemas de geração e transmissão de energia, além de atuar nas áreas de diagnóstico médico, soluções de infraestrutura e industriais.

Como estratégia de longo prazo, a organização investe em três campos de conhecimento: eletrificação, automação e digitalização. Para intensificar o potencial de mercado de cada um desses segmentos, suas atividades foram agrupadas em nove divisões — a gestão dos serviços relacionados à saúde, no entanto, é separada das demais.

Dessa forma, de acordo com o site da empresa, a atuação da Siemens foi organizada nos seguintes grupos:

- "Power and Gás" - dedicado a oferecer produtos e soluções aos clientes que pertencem ao mercado de óleo e gás, funcionando de acordo com a demanda.

- "Wind Power" — responsável pelo fornecimento de soluções de energia eólica, possui como foco principal reduzir os custos de maneira que essa 
fonte de energia limpa e renovável se torne competitiva em relação a outras fontes convencionais.

- "Power Generation Services" — oferece assistência especializada de equipamentos de geração de energia dentre os mais diversos setores.

- “Energy Management" — divisão responsável por oferecer produtos, serviços, soluções e sistemas para transmissão e distribuição de energia elétrica.

- "Building Technologies" — negócio de edificações e infraestrutura, age como parceira em tecnologia, consultoria, fornecimento de produtos, integração de sistemas e prestação de serviços.

- "Mobility" — produtos, soluções e serviços ligados à mobilidade, visando otimizar a eficiência e integração no transporte por via ferroviária e rodoviária.

- "Digital Factory" - mercado de software, hardware e serviços baseados em tecnologia para otimizar a produção de empresas.

- "Process Industries and Drive" — oferece tecnologia inovadora e integrada para produtos, processos e instalações.

- “Financial Services” — Oferece soluções financeiras a outras empresas.

Para funções de apoio comuns a todas divisões de negócios foi estruturada a área de negócios centrais, chamada de Corporate Units. Ela engloba os departamentos de recursos humanos, compliance, segurança da informação, tecnologia da informação, controle de risco, jurídico, sustentabilidade, tributação, segurança, governança e financeiro.

A Siemens iniciou seu primeiro projeto no Brasil em 1867 e foi responsável pela construção da primeira linha telegráfica no país. Seu primeiro escritório, porém, foi aberto somente em 1895, no Rio de Janeiro, com o objetivo de lucrar com a demanda elétrica que crescia devido à urbanização da cidade. Hoje, se destaca como a maior empresa de tecnologia integrada do mercado brasileiro e possui mais de 5 mil funcionários distribuídos em 12 fábricas, 7 centros de P\&D e 13 escritórios regionais. 


\subsection{Fundação Siemens}

Criada em 1986, a Fundação Peter Von Siemens tem como objetivo colaborar com o desenvolvimento da sociedade. Isso porque, considerando-se como parte integrante de uma comunidade, a fundação sente-se responsável por sua conjuntura e deve agir como agente transformador.

Mantida pelo Grupo Siemens no Brasil, a fundação sofreu uma reestruturação e a sua forma de agir ficou mais estratégica e voltada aos valores da organização, tornando possível a criação de valor compartilhado. Sua receita vem basicamente de doações feitas pelas empresas do grupo. O desenvolvimento local e a educação são seus principais focos e são feitos por meio de tecnologias básicas que buscam impactar a sociedade de uma maneira positiva.

Em 2004, a fundação recebeu o título de Organização da Sociedade Civil de Interesse Público (OSCIP) . Uma OSCIP ajuda empresas a se mobilizar e adotar uma forma de gestão mais socialmente responsável, além de formar uma parceria a concepção e idealização de uma sociedade mais justa e solidária. 


\section{Diagnóstico da situação problema e oportunidade}

O objetivo desse capítulo é descrever o processo de implantação do programa de voluntariado a partir de uma abordagem qualitativa. Por se tratar de uma pesquisa retrospectiva, aquelas que exploram fatos do passado e atuais ,foram utilizados diferentes métodos de coleta de dados.

Num primeiro momento foi necessário levantar os tópicos relevantes do processo de implantação a partir da bibliografia das principais instituições que incentivam empresas a fazerem investimentos sociais.

No intuito de avaliar o contexto que levou a Siemens a se engajar, e obter informações da evolução do programa de voluntariado , foram realizadas análises de seus relatórios de sustentabilidade dos anos de 2012, 2014, 2015 e 2016. O portal de voluntários da empresa também foi investigado dentro desta pesquisa .

O material obtido serviu como base para realizar entrevistas com o representante do voluntariado no Rio de Janeiro, Ramon Martins. As entrevistas foram feitas com perguntas abertas, pessoalmente e por telefone nos meses de abril e maio. E foram abordados temas sobre a operacionalização do programa, da estrutura, da elaboração dos projetos e das formas de comunicação e práticas para engajar colaboradores.

Objetivando apresentar dados com encadeamento lógico foram utilizadas como referência as etapas de implantação do programa de voluntariado indicadas pelo Instituto Ethos de Empresas e Responsabilidade Social, e em seguida relatando o procedimento adotado pela Siemens e posteriormente apresentando alguns dos seus principais projetos em execução. 


\subsection{Reflexão dos motivos para se implantar o programa de voluntariado empresarial.}

"Promova uma reflexão dentro da sua empresa sobre a missão da organização e sobre responsabilidade social empresarial. Conquiste aliados dentro da hierarquia, defina prioridades institucionais e comece a trabalhar a ideia de a empresa ter um programa de voluntariado.”(Goldberg 2001, p.39)

A reflexão sugerida nesta etapa é de extrema importância. Mergulhar dentro da missão, visão, valores e responsabilidade empresarial auxilia a compreender, de forma assertiva, quais os motivos do programa de voluntariado, e como fazer a conexão deles junto às prioridades da organização.

Segundo a Siemens, responsabilidade, excelência e inovação são os valores que guiam o conglomerado em seus negócios. Em seu site a empresa declara que sua missão é feita de forma que "por meio de nossa rede global de inovação e forte presença local, reunimos e desenvolvemos competências e conhecimento, dentro de uma organização de alta performance, objetivando gerar o mais elevado nível de valor agregado para nossos clientes, colaboradores, acionistas e sociedade."

A estratégia da Siemens é baseada em: foco no cliente e no negócio; na cultura empreendedora; na governança e no seu modelo de gestão. O último, adotado pela empresa no mundo inteiro, é chamado de One Siemens e foi criado em 2010 para responder às necessidades futuras da organização diante das novas tendências como globalização, urbanização, mudanças demográficas e climáticas. Agindo dessa forma a empresa espera ser capaz de assegurar o seu desenvolvimento sustentável e crescimento da eficiência de capital.

A Siemens, também em 2010, implementou o Programa Mundial de Sustentabilidade e a matriz brasileira reestruturou seus modelos de negócios de acordo com as diretrizes globais. E em 2012, com a finalidade de aumentar a sinergia entre as demais áreas a cerca do tema de desenvolvimento sustentável foi criado o departamento de sustentabilidade que é segmentado em setores de meio 
ambiente, desenvolvimento de portfólio ambiental e cidadania corporativa. Tal departamento faz parte da estrutura central da Siemens, a mesma que serve de apoio em seus diferentes negócios. O programa voluntário foi elaborado pela área de cidadania corporativa com o propósito de alinhar a Siemens Brasil com a estratégia da organização mundial.

\subsection{Comitê}

"Reúna uma equipe de funcionários e forme o primeiro comitê de trabalho. O comitê vai mapear as ações sociais já realizadas pela empresa, identificar oportunidades e interesses de atuação voluntária e propor um plano de ação que também leve em consideração às expectativas dos funcionários." (Goldberg 2001, p.39)

É fundamental criar um comitê que atue como fórum de ideias e que possibilite discutir o planejamento e bases do programa. Dessa forma, fortalecerá e incentivará o engajamento dos colaboradores, o que é essencial visto ser um trabalho voluntário. $\mathrm{O}$ comitê se estrutura, geralmente, através do envolvimento de colaboradores de diferentes setores e hierarquias da organização. São pessoas que entendem bem a rotina empresarial, fator importante na hora de alinhar os objetivos do programa e da empresa.

Para desempenhar a função do comitê no caso da Siemens Brasil foi preciso instituir redes locais, situadas em cada um dos treze escritórios regionais. Essas redes são formadas por dois ou três colaboradores voluntários, nomeados como representantes pelo gestor de cidadania corporativa. Cabe a cada uma delas tecer uma série de ações, tais como fomentar a ação social e o engajamento, participar de capacitações e realizar treinamentos sobre política do voluntariado para os colaboradores, além de oferecer o suporte técnico necessário. 
No Brasil, a responsável pelas 13 redes locais é a coordenadora de voluntários, Júlia Ferreira, que possui a função de facilitar o andamento do programa e promover o desenvolvimento dos voluntários. Tanto o gestor de cidadania corporativa como o coordenadora de voluntários pertencem a área de cidadania corporativa, cuja direção fica sob responsabilidade de Henrique Paiva.

\subsection{Recursos}

"Faça um exercício de planejamento e defina com que a empresa precisará comparecer em termo de recursos financeiro, materiais e humanos, para que o programa se desenvolva." (Goldberg 2001, p.39)

Nesse ponto, é importante levantar todos os recursos — sejam eles humanos, físicos ou financeiros-que possam ser necessários para o andamento adequado do programa. É provável que seja preciso fazer investimentos e adquirir bens e equipamentos. Deve-se, também, definir como serão alocados os recursos financeiros para a execução dos projetos.

No que diz respeito aos recursos humanos, é preciso buscar pessoas comprometidas com a causa. É necessário, ainda, a existência de treinamentos e capacitação dos voluntários, além de consultoria externa de profissionais especializados, caso haja necessidade.

Na Siemens, a forma definida para captar recursos físicos e financeiros é por meio de uma estrutura interna de financiamento para projetos. A tramitação do processo segue alguns passos. O colaborador voluntário solicita recursos para sua respectiva área por meio de um processo aplicado pelo departamento de compliance. É preciso preencher toda uma documentação de "doação", discriminando as necessidades, o que é o projeto e para qual empresa será a doação. O compliance faz a análise e, se pelo menos dois funcionários aprovarem a doação, será emitida uma nota fiscal confirmando o donativo. Cada área define o orçamento de acordo com seus objetivos . 
Ramon Martin, representante de rede local no Rio de Janeiro, sinalizou, durante a entrevista, que a verba do programa voluntariado não é muito expressiva e o montante é utilizado para cobrir custos administrativos e de marketing. Porém, alegou:

"A empresa pode fornecer recursos ao programa de voluntariado dependendo da situação econômica do momento, mas, por estarmos em um momento de recessão, acaba não sobrando tanto dinheiro para voluntariado, então os departamentos mantém apenas seus custos básicos"

Outra possibilidade para levantar recursos financeiros - mesmo que não seja de uma maneira formal - é quando alguns colaboradores se mobilizam entre si e colocam recursos próprios no momento em que o programa já havia sido implantado. É uma atitude que ocorre por conta do total engajamento dos voluntários.

Em relação aos aspectos materiais e físicos, a empresa é encarregada de supri-los para o andamento do projeto. Sendo necessário disponibilizar, por exemplo, sala para reuniões e treinamentos, equipamentos, mobiliário, ferramentas, impressoras, papéis e qualquer outro material de escritório para funções administrativas

Um dos aspectos importantes a ser salientado no modelo de voluntariado da Siemens Brasil é sua parceria com a Fundação Siemens. Apesar da ter sido criada pela Siemens e de compartilhar os mesmos valores e objetivos, como as ações sociais, no entanto, a fundação não é diretamente ligada à empresa. Como instituição social, tem gestão e colaboradores próprios. Apesar de ambas terem o mesmo nome, a Fundação Siemens é um organização à parte e é reconhecida como Organização da Sociedade Civil de Interesse Público, uma espécie de ONG de iniciativa privada. Ela é o agente facilitador que oferece o suporte técnico a projetos do programa de voluntariado da Siemens. Ela é co-responsável na gestão de algumas ações e oferece treinamento e capacitação aos voluntários.

Em recursos humanos, no sentido de quem irá executar as tarefas dos projetos, temos os colaboradores que irão aderir ao programa e os departamentos 
que quiserem implantar um projeto próprio. No modelo programa que a Siemens Brasil elaborou, isso é possível e será abordado a frente. É importante frisar que todas ações ocorrem no horário de trabalho, o que significava que essas horas são doadas pela Siemens. Só é necessário a aprovação do gestor direto do voluntário.

O colaborador, entretanto, pode optar por não participar para não comprometer sua estabilidade no emprego. $O$ funcionário pode não querer prejudicar sua imagem com seus superiores por usar o horário do expediente para ações sociais. Vai depender de como é a cultura do voluntariado em cada setor da empresa. Isso é possível concluir a partir da seguinte afirmativa do entrevistado:

“...no fundo, todo mundo ali trabalha, aquilo ali é seu ganha pão, è a sua vida, então, o funcionário primeiro vai ter que pensar na sua família ou como vai ser visto dentro da empresa, ele não vai fazer trabalho voluntário se for mal visto por isso..."

\subsection{Difusão}

"Difunda amplamente na empresa a proposta de fomentar o voluntariado lançando uma pesquisa junto aos funcionários. Muito mais do que oficializar suas intenções na área, a pesquisa levantará experiências pré-existentes e os interesses do grupo." (Goldberg 2001, p.39)

É interessante para a empresa aplicar uma pesquisa afim de levantar informações acerca das expectativas e experiências de cada colaborador. Isso permitirá fazer um diagnóstico da receptividade à proposta. Entretanto, segundo o Ruth Goldeberg, há empresas com programas bem sucedidos que não aplicaram essa etapa. (Goldberg 2001, p.39)

Uma das formas iniciais de comunicação que a empresa usou para divulgar seu programa de voluntariado foi através do email corporativo, informando aos colaboradores detalhes da iniciativa. $\mathrm{O}$ entrevistado relatou que a primeira forma de fomentar o engajamento foi feita através de um programa de incentivo interno 
já existente, chamado sistema de pontos. Nesse sistema os pontos são convertidos em prêmios. Ramon definiu o sistema da seguinte maneira: “.. É como se fosse um programa de milhagem, em que as horas gastas com trabalho voluntário são convertidas em uma pontuação que pode ser trocada por prêmios. Eu, por exemplo, já troquei por um pen drive, um mouse e pelo som do meu carro."

O entrevistado afirmou que já havia colaboradores que tinham participado de ações feitas pelo instituto Siemens e que, entre seu colegas de trabalho, havia aqueles que se engajavam em ações sociais antes da Siemens começar a praticar as suas. A campanha de comunicação foi um elemento que serviu para reunir esse grupo de pessoas interessadas no voluntariado, mas também atraiu novos colaboradores, pelo menos no caso do Rio de Janeiro.

\subsection{Necessidades da comunidade}

"Busque informações sobre que tipo de ajudas a comunidade precisa." (Goldberg 2001, p.39)

Para atingir os resultados esperados com o programa de voluntariado é preciso levar em consideração as necessidades reais da comunidade atendida. As ações não se limitam apenas a atos de solidariedade e cidadania, seu real propósito è atender uma demanda que cause impacto e ajude a comunidade a se desenvolver.

Algumas empresas pré-determinam a temática de seus projetos no programa voluntário, como é o caso da Siemens. Acreditando que é por meio da base escolar que será formado o futuro promissor do país - visto que é uma empresa de engenharia e precisará de engenheiros no futuro - a Siemens escolheu a educação como foco principal de suas ações. E, por estar em sintonia com sua área de negócios, também optou por desenvolver projetos focados em tecnologias básicas, voltadas a promover a qualidade de vida. $\mathrm{O}$ foco é atender às comunidades que ficam próximos das instalações da Siemens, não se limitando, porém, em atuar em outras localidades. 
Uma das funções do entrevistado, como representante da rede local, é entrar em contato e visitar instituições que possam ser beneficiadas, ao lado de outros colaboradores voluntários. A partir desses encontros, ele vê-se há a possibilidade de elaborar um projeto, alinhando necessidades locais com objetivos estratégicos do programa. :

“...a primeira abordagem quando você vai conversar com uma instituição, que você quer ajudar, uma comunidade, é você mapear os problemas. Qual é o tipo de ajuda que a comunidade precisa, ouvir o que ela necessita. Depois você volta pra Siemens, dá uma olhada nas capacidades do seu quadro de voluntários e tenta surgir com um projeto ou ação, que atenda aquela comunidade...”

\subsection{Projeto do programa voluntário}

“Reúna informações. Cruze os interesses da empresa, dos funcionários e redija um projeto para seu programa de voluntariado. (Goldberg 2001, p.40)

Esse passo serve como guia para a implantação do programa de voluntariado empresarial. O projeto mencionado, no entanto, não se refere às ações que serão desenvolvidas. Ele, na verdade, sintetiza de forma clara e concisa todas informações necessárias agrupadas - como objetivos e estratégias, atividades a serem executadas, recursos disponíveis e resultados esperados.

De acordo com o portal da o Siemens objetivo da empresa é ser reconhecida como exemplo de cidadania. É por meio da implantação do programa que a empresa pretende alcançá-lo. Para que isso seja possível, foram criadas estratégias como: parceria com instituições; engajamento dos colaboradores; apoio da Fundação Siemens e a estrutura de financiamento de projetos.

A primeira das ações é a relação com as instituições que serão beneficiadas como escolas, universidades, centros de profissionalização e outros lugares onde seja possível aplicar os princípios que a Siemens Brasil pretende difundir. A segunda se baseia no engajamento gerado nos colaboradores por meio das competências técnicas usadas em prol da sociedade. A terceira é a expertise e experiência que a Fundação Siemens agrega. E, por último, é a estrutura de 
financiamento que dá autonomia a cada departamento para investir em projetos próprios.

Os projetos desenvolvidos são as atividades chaves a serem executadas. Definindo que $80 \%$ deles serão focados em educação, $20 \%$ em tecnologias básicas, e utilizando como principais recursos o apoio da Fundação Siemens somados a proatividade dos voluntários, espera-se ter como resultado:

-O engajamento de stakeholders — Entende-se como conhecer quem eles são, quais são suas expectativas e, a partir delas, estabelecer diálogos. Esse contato permite prevenir possíveis conflitos e adquirir bases que possam melhorar o processo decisório e evitar riscos;

-Confiança pública/credibilidade/reputação - Para uma empresa que possui o seu negócio intimamente ligado à inovação, a construção da sua imagem tem um papel fundamental para a competitividade.

- Cultura e valores - Consolidar a cultura e valores da empresa nos colaboradores e nos beneficiados pelo programa.

-Engajamento dos colaboradores — Adesão do maior número possível de voluntários.

\subsection{Gerenciamento dos projetos do programa de voluntariado}

"Ponha o programa pra funcionar. Ė hora de começar a gerenciar tudo aquilo que você previu fazer.” (Goldberg 2001, p.40)

Para coordenar os projetos que irão aparecer, a empresa precisará de um colaborador ou contratar alguém que abrace a causa com seriedade. É interessante que o coordenador do projeto possua certas competências e características, como carisma, capacidade de liderança, empatia, habilidade de trabalhar em equipe, pragmatismo, ser ágil na solução de problemas e ter comprometimento. Os projetos podem ser submetidos ao programa da Siemens por meio de três públicos e atendendo ao seguintes critérios de gestão:

-Colaborador - O funcionário pode propor ações, projetos ou atividades na rede local, desde que se comprometa com a gestão. A Fundação Siemens e a rede local darão qualquer suporte técnico necessário. 
-Siemens Brasil - Os departamentos que se demonstraram interessados também podem propor projetos. A gestação fica a encargo da área que fez a proposta, sendo necessário a nomeação de um coordenador para o projeto. Nesse caso a Fundação Siemens e as redes locais também oferecem apoio técnico.

-Fundação Siemens - Os projetos já existente ou a serem realizados estão disponíveis aos colaboradores. Para fazer parte é preciso entrar em contato por meio da rede local. A gestão é encarregada pela fundação e as rede locais oferecem suporte técnico quando necessário.

Observamos então que a iniciativa para os projetos parte dos colaboradores e dos departamentos. No entanto, além do suporte, cabe a rede local engajá-los, para que o programa flua. Podemos ver como exemplo o seguinte trecho da entrevista:

“...a escola tinha os aparelhos de ar condicionado quebrados, estava precisando de uma pintura, estava com uma ideia legal de fazer um encanamento da água do ar condicionado, varias necessidades. Então o que posso fazer? Vi que tinha muita coisa de manutenção predial e falei com o chefe da manutenção do prédio da Siemens. Perguntei se teria como me ceder os funcionários, se eles quisessem participar por vontade própria para ajudarem em atividades específicas que eles conseguem fazer daqui. Ele disse que concedia, era só a gente organizar e ver se o pessoal ia se escrever, ai todo mundo se escreveu."

De acordo com Ramon, as rede locais são fundamentais para o desenvolvimento de projetos, mesmo sem desempenhar a função de criá-los.

\subsection{Valorização, reconhecimento e comunicação.}

"Reforce suas práticas de valorização, reconhecimento e comunicação. Institua política para essas áreas, pois elas serão responsáveis pela manutenção e por grande parte do sucesso" (Goldberg 2001, p.40)

Para que o programa tenha êxito e se perpetue é essencial estabelecer uma boa política de reconhecimento e comunicação. O simples ato de ser solidário e o que se ganha pessoalmente com isso são elementos incentivadores, mas quando há reconhecimento, existe um impacto maior. Adquirir a prática de valorizar o 
empenho e as conquistas do seu time de voluntários é uma excelente forma de mantê-lo atuante. E através de meios de comunicação é possível trazer a valorização e o reconhecimento. O seu propósito, no entanto, vai além. É fundamental ter $\mathrm{o}$ diálogo com público interno para incentivar $\mathrm{o}$ engajamento. Uma boa linha de comunicação dá visibilidade ao programa, mobiliza os colaboradores à adesão, ajuda a divulgar suas informações funcionais e permite a troca de experiências.

A Siemens consciente do resultado dessas práticas passou a aplicá-las em seu modelo. Umas das metas da empresa é que $10 \%$ dos seu funcionários participem do grupo de voluntários. Em setembro de 2014, criou uma plataforma online para fomentar o interesse do seu voluntariado. Nesse ambiente virtual são colocadas informações das ações presentes e futuras, e nele também é possível que os funcionários criem um perfil próprio e inscrevam projetos de seus interesses. O intuito é que funcione como uma rede social, onde todos se sintam mobilizados a trocarem experiências. Nesse portal há também a possibilidade do voluntário atribuir duas espécies de selos. O primeiro é para agradecer algum tipo de ajuda que lhe foi dada. Já o segundo selo é o de reconhecimento, dado aos funcionários que se destacam. Há também um espaço dedicado para cada rede local atuar, e isso deu autonomia para o desenvolvimento de um trabalho mais ativo.

No entanto, mesmo com o encurtamento da distância gerado por esse meio de comunicação, o entrevistado afirmou que as redes locais apresentam diferentes níveis de engajamento. Isso foi confirmado através do portal. Enquanto em Anhanguera possui 394 voluntários e Jundiaí,117, vemos 7 redes locais em que não há mais do que 10 em cada uma.

O entrevistado falou ainda que nunca foram realizadas pesquisas internas para saber a opinião dos colaboradores sobre o programa voluntário. Pode-se deduzir que não há uma real preocupação para avaliar como cada localidade enxerga as iniciativas sociais.

O diálogo da empresa Siemens com seu público externo é feito principalmente através de seu relatório de sustentabilidade. Utilizado como 
instrumento de promoção de suas práticas sociais, esse relatório é uma forma da organização se mostrar transparente e prestar conta dos resultados alcançados pelo seu programa.

A empresa possui algumas maneiras para recompensar seus empregados. Como exemplo há o prêmio Werner Von Siemens Award ,no qual qualquer funcionário pode concorrer apresentando um projeto inovador atrelado ao valores da Siemens. O vencedor viaja à Alemanha para ser premiado.

Há também o sistema de pontos, mencionado anteriormente, em que as horas gastas com trabalho voluntário são convertidas em uma pontuação e esses pontos, trocados por prêmios .

Segundo o Ramon Martim, não há uma política de reconhecimento bem definida, na qual os voluntários possam participar das ações sociais e se sentir seguros em relação aos seus superiores, que não julgaram tal ação como obstáculo dos seus resultados. Dessa forma, o entrevistado afirma:

“ ...o gestores precisam de algum tipo de reconhecimento por estar cedendo seus funcionários, e o funcionário tem que ter um bom reconhecimento pelo gestor para estar cedendo suas horas no voluntariado, se não vira aquela situação: "pô, caraca, não vai trabalhar". Então tem que ser algo que seja visto como beneficio para todos "

Podemos deduzir então que a falta de uma política de reconhecimento concreta, em que o gestor veja valor em ceder seu funcionário, afeta o número de pessoas dispostas a trabalharem como voluntárias.

\subsection{Parcerias}

"Troque experiências e conhecimentos com outras empresas e organizações atuantes no setor. Isso ajuda o seu programa de voluntariado a crescer e também os programas de outras empresas." (Goldberg 2001, p.40) 
A ideia de formar uma parceria entre empresas e organizações sugere propósito de compartilhar interesses comuns. Fomentar parcerias possibilita desenvolver trabalhos em rede, pois promover o contato com outras instituições incrementa o debate, além de fortalecer a prática do movimento de voluntariado. Isso porque discutir sobre o assunto ajuda a aprimorar os níveis de conhecimento pela troca de experiências e permuta de tecnologias.

Em 2016 a Siemens fechou uma parceria com o grupo Fleury em uma ação que promoveu o mutirão de exames médicos pelo sertão brasileiro. O grupo entrou com uma equipe de médicos e técnicos voluntários enquanto a Siemens forneceu as tecnologias desenvolvidas na área da Medicina. União estratégica na qual duas empresas puderam aplicar suas competências em benefício às comunidades que precisavam de assistência.

Outro exemplo de parceria com saldo positivo foi formada entre a Fundação e a empresa Siemens, e a Fundação Iochpe, cujo resultado é Escola Formare Siemens. Tal programa nasceu de instituições com valores alinhados no sentido de desenvolver projetos focados em educação. A Fundação Iopche, habituada a também realizar investimentos sociais em cultura e bemestar social, foi criada pelo grupo empresarial Iochpe-Maxion S/A. A Formare, um programa criado pela Fundação Iochpe, visa encontrar novas empresas parceiras para profissionalizar jovens de baixa renda profissional.

Por estar a frente desse projeto, a gestão e o investimento financeiro ficaram em responsabilidade da Fundação Siemens, sendo ela responsável pela construção da escola com toda infraestrutura necessária no Complexo industrial da Siemens em Jundiaí. A empresa Siemens entrou nessa parceria cedendo seu colaboradores voluntários para ministrar as aulas, enquanto a Fundação Iochpe deu suporte às parte metodológicas e didáticas durante sua implantação.

O curso tem 9 meses de duração e oferece diplomas em montagem eletromecânica e de assistente de produção. Um total de 480 
jovens já conseguiram seu diploma e 143 funcionários contribuíram. Em 2016, o projeto foi reconhecido com o prêmio Werner Von Siemens Awards.

\subsection{Exemplos de projetos desenvolvidos após a implantação do programa}

Os dados a baixo referentes aos projetos em andamento foram levantados através do portal de voluntários da Siemens.

\section{EduComÉtica}

Projeto desenvolvido pelo departamento de compliance em 2014 e ainda em atividade, sua finalidade é transmitir princípios de ética e integridade para estudantes de escolas e universidades. Os colaboradores voluntários recebem um treinamento prévio da área de compliance, e realizam palestras para debater sobre o tema e conscientizar os jovens sobre esses princípios. Desde que a iniciativa foi lançada, 600 estudantes já foram beneficiados, 35 colaboradores apoiam a causa e o projeto foi aplicado em 12 instituições.

\section{Projeto voluntário Multiplicadores de Inteligência Emocional}

Uma parceira da Fundação Siemens com o programa de voluntariado da própria empresa, iniciada em 2013. A Fundação oferece capacitação em inteligência emocional para voluntários. E esses passam os conhecimentos adquiridos em escolas através de dinâmicas recreativas. Já foram realizadas duas ações que mobilizaram 31 colaboradores.

\section{Ações Green Team}

O Green Team é uma iniciativa dos colaboradores de Manaus e que foi replicada pelas outras localidades. As ações Green Team consistem em criam projetos focados em conscientizar e estimular a preservação do meio ambiente. Em 2015, um grupo de colaboradores de diferentes departamentos se mobilizaram e desenvolveram uma gincana sustentável para 17 crianças da Albino 
de Melo de Oliveira em Jundiaí. O objetivo era abordar o tema sustentabilidade e meio ambiente através de atividades lúdicas.

\section{Social Responsability}

O projeto é uma iniciativa do departamento de RH,onde seus estagiários desenvolvem projetos sociais na comunidade local. O Social Responsibility tem como finalidade, além de contribuir com a sociedade, desenvolver competências profissionais importantes em seus jovens. Já foram realizadas 23 ações, que mobilizaram 198 voluntários , e3.829 pessoas foram beneficiadas.

\section{Social Finance}

Todo ano, algumas áreas financeiras da Siemens promovem um dia de voluntariado em alguma escola. Eles realizam atividades ligadas a plantio, pintura, reparos e pequenas reformas com o objetivo de revitalizar a escola. Já ocorreram 4 ações, que envolveram 190 funcionários e beneficiaram 1.800 crianças. 


\section{Análise da situação e proposta de solução}

\subsection{Decisão de implantação e definição da temática}

Independentemente do ramo em que atue, toda empresa está inserida no meio sociocultural e presta serviços à sociedade. Além disso, a responsabilidade social corporativa se tornou, nos dias atuais, mais uma demanda necessária para as empresas manterem competitividade e perpetuidade no mercado. Hoje, os principais stakeholders das organizações, seja os consumidores, simpatizantes da marca, funcionários ou seus fornecedores, possuem a expectativa de que as empresas ampliem o seu comportamento nos níveis da ética. Segundo Carroll (1999, p.282):

“Os negócios estão sendo chamados para assumir responsabilidades amplas para a sociedade como nunca antes e para servir a ampla variação de valores humanos (qualidade de vida além de quantidade de produtos e serviços). Os negócios existem para servir a sociedade; seu futuro dependerá da qualidade da gestão em responder as mudanças de expectativas do público”.

Na Siemens percebe-se que existe uma preocupação no sentido de criar valor e não apenas riqueza. Quer dizer, agregar uma imagem positiva a fim de ganhar o respaldo e reconhecimento diante de seus consumidores, gerando a contribuição social, predisposição em ser útil e surpreender positivamente o público. No entanto, a decisão de praticar o programa de voluntariado não se dá apenas por razões humanitárias. A empresa foi capaz de identificar uma oportunidade de alinhar os seus objetivos corporativos com iniciativas sociais, o que traz entre diversos benefícios uma vantagem competitiva. 
Pela tabela presente no relatório BISC (2016, P.90), observamos que as temática escolhidas pela empresa, educação e desenvolvimento comunitário por meio de sua tecnologias básicas, são aquelas que outras organizações acreditam que mais impacta em seus stakeholders. A partir desse gráfico podemos ver o percentual de concordância entre as empresas em relação ao impacto da temática escolhida tem sobre cada Stakeholder ( $a$ empresa pode assinalar mais de stakeholders por temática, o percentual apresenta o consenso entre elas da influência daquela temática sobre aquele Stakeholder específico).

\begin{tabular}{|c|c|c|c|c|c|c|c|}
\hline & \multicolumn{3}{|c|}{ (- 0 a $10 \%$ das empresas } & \multicolumn{2}{|c|}{$11 \%$ a $24 \%$ das empresas } & \multicolumn{2}{|c|}{$25 \%$ e mais das empresas } \\
\hline & FORNECEDORES & $\begin{array}{l}\text { COLABORA- } \\
\text { DORES }\end{array}$ & CUENTES & ACIONISTAS & $\begin{array}{l}\text { UDERES DAS } \\
\text { EMPRESAS }\end{array}$ & $\begin{array}{c}\text { COMUNIDADES } \\
\text { DO } \\
\text { ENTORNO }\end{array}$ & $\begin{array}{l}\text { ORGANIZAÇŌES } \\
\text { GOVERNAMEN- } \\
\text { TALS }\end{array}$ \\
\hline Educaçáo & $13 \%$ & $38 \%$ & $19 \%$ & $30 \%$ & $36 \%$ & $38 \%$ & $25 \%$ \\
\hline Infraestrutura (urbana ou rural) & $6 \%$ & $13 \%$ & $6 \%$ & $13 \%$ & $6 \%$ & $6 \%$ & $6 \%$ \\
\hline Geraçáo de renda & $13 \%$ & $13 \%$ & $19 \%$ & $6 \%$ & 13\% & $25 \%$ & $0 \%$ \\
\hline Assistência social & $6 \%$ & $19 \%$ & $13 \%$ & $0 \%$ & $6 \%$ & $19 \%$ & $25 \%$ \\
\hline Meio ambiente & $19 \%$ & $31 \%$ & $25 \%$ & $19 \%$ & $25 \%$ & $13 \%$. & $13 \%$ \\
\hline Desenvolvimento comunitário/económico & $31 \%$ & $13 \%$. & $38 \%$ & $25 \%$ & $25 \%$ & $56 \%$ & $25 \%$ \\
\hline Saúde & $0 \%$ & $0 \%$ & $13 \%$ & $6 \%$ & $6 \%$ & $25 \%$ & $25 \%$ \\
\hline Combate à pobreza eà fome & 085 & $0 \%$ & $6 \%$ & $0 \%$ & os & $25 \%$ & $19 \%$ \\
\hline Moradia & $00 \%$ & $0 \%$ & $6 \%$ & $0 \%$ & 6\% & 13\%. & $6 \%$ \\
\hline Esporte e lazer & OS. & $6 \%$ & $13 \%$ & $08 \%$ & $6 \%$ & $19 \%$ & os \\
\hline Apoio à gestăo de politicas públicas & $0 \%$ & $6 \%$ & $0 \%$ & 6\% & 13\% & $6 \%$ & $19 \%$ \\
\hline Defesa de direitos & $0 \%$ & $31 \%$ & $13 \%$ & $6 \%$ & $13 \%$ & $19 \%$ & $6 \%$ \\
\hline Igualdade de gènero & $13 \%$ & $31 \%$ & $6 \%$ & $13 \%$ & $13 \%$ & $0 \%$ & 6\% \\
\hline Gestăo sustentivel de água e saneamento & $19 \%$ & $19 \%$ & $6 \%$ & $0 \%$ & $6 \%$ & $19 \%$ & $6 \%$ \\
\hline Não sabe & $31 \%$ & $13 \%$ & $25 \%$ & $31 \%$ & $25 \%$ & $19 \%$ & $35 \%$ \\
\hline
\end{tabular}

Tabela 1 BISC 2016, Comunitas 


\subsection{Estrutura}

Dentro das organizações há diversos departamentos que podem ser responsáveis pelo programa de voluntariado. O modelo aplicado pode variar de acordo com os objetivos estratégicos, seja o programa podendo ser gerido por diferente departamentos, do marketing ao recursos humanos, ou até na criação de uma nova estrutura. De acordo com o gráfico do relatório CBVE (2016, p.09) podemos ver que por uma margem expressiva os programas ficam a encargo do Departamento de Responsabilidade Social e Sustentabilidade. E é dessa maneira que é feito na Siemens.

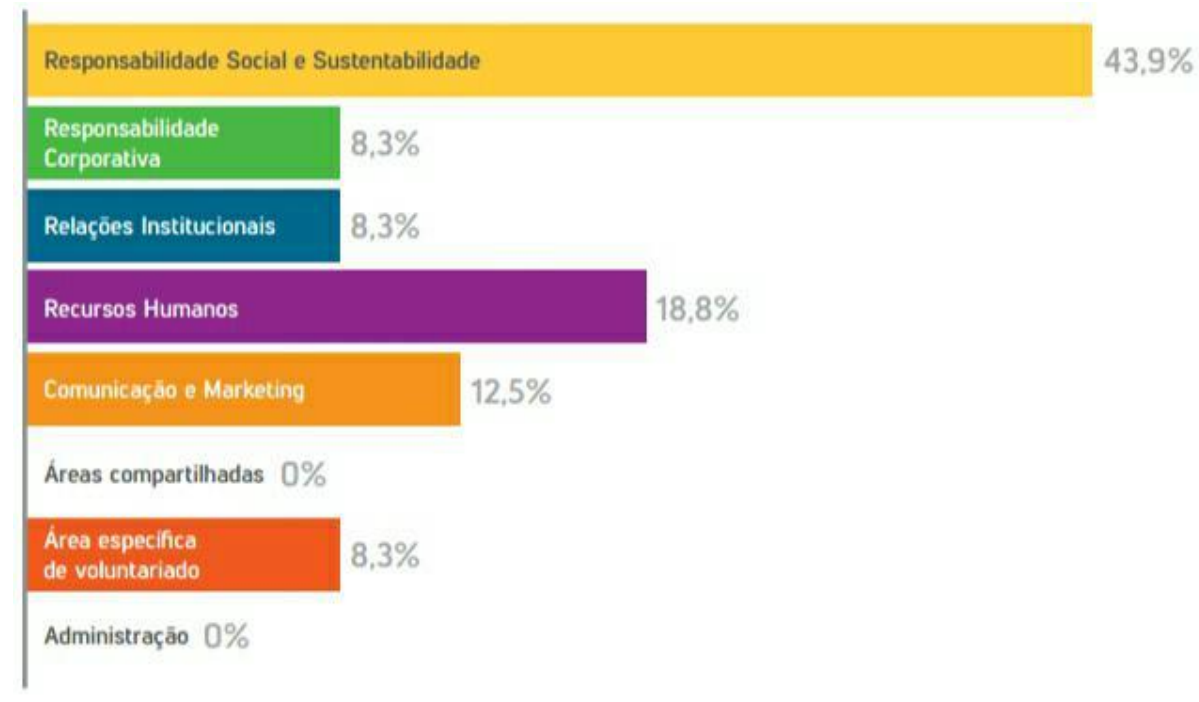

Figura 2 Gráfico relatório BISC 2016 p.09

É importante que haja sinergia entre a área escolhida para coordenar o programa com as demais áreas da empresa, e que todas estejam envolvidas com a causa do voluntariado. A falta de articulação entre áreas é um fator que pode abalar o funcionamento do processo de voluntariado. No caso da Siemens, a área que coordena é a de Cidadania Corporativa e está localizada em São Paulo, enquanto os demais departamentos estão espalhados por todo território brasileiro. 


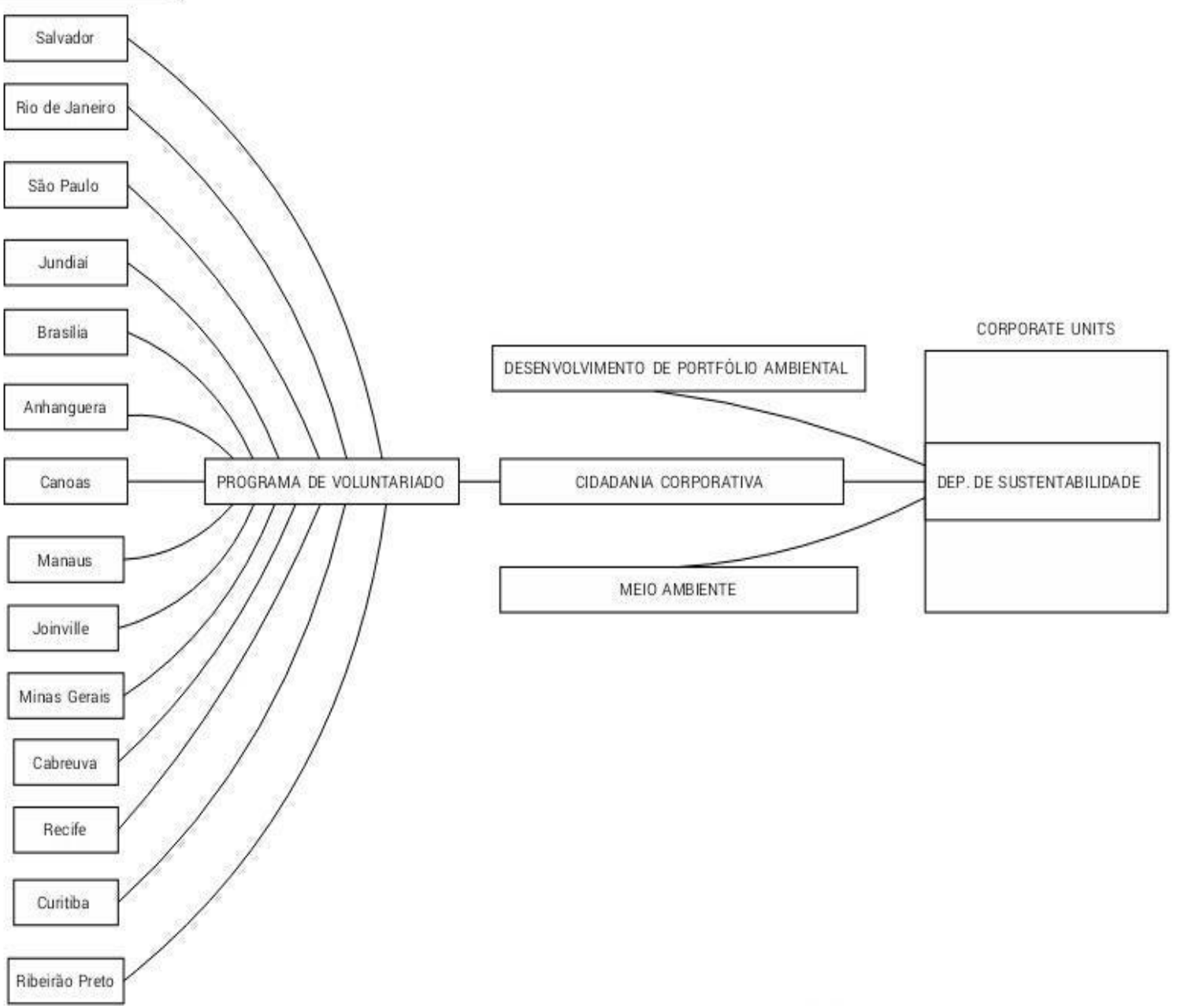

Figura 3 Organograma departamento sustentável

As redes locais foram importantes para o programa por conta do tamanho da estrutura da Siemens no Brasil. Elas agiram como instrumento de gestão e puderam incentivar mais colaboradores a se tornarem voluntários. Contudo, averiguamos uma desproporção muito grande de níveis de engajamento entre elas, pela diferença de números de voluntários. As mais atuantes estão na região sudeste do que nas demais.

Uma sugestão para mitigar esse desequilíbrio seria promover reuniões mensais por vídeo conferências, onde cada uma poderia expor seus resultados, como uma forma de incentivo e de aumentar a eficiência do programa em todo território 


\subsection{Recursos}

Segundo o Instituto Votorantim, a forma como a Siemens define seu orçamento pode ser enquadrada como descentralizada. De acordo com os objetivos específicos de cada unidade local, um orçamento próprio é definindo, considerando os objetivos estratégicos da organização. O risco, porém, é ocorrer um engajamento de forma desigual, o que é desfavorável. (Guia Votorantim 2014, p.26)

Tomemos como exemplo a área de compliance cuja função é fazer a organização seguir conforme as normas legais e regulamentações, através do projeto EduComÉtica. Ela conseguiu consolidar princípios de ética e integridade necessárias para seus voluntários. Isso porque foram feitos treinamentos para ministrar palestras voltadas para os alunos das instituições atendidas.

De certa forma, a temática definida em educação possibilitou que os departamentos capacitassem os voluntários em habilidades específicas de seu campo de atuação. Esse procedimento leva o fortalecimento da organização como um todo.

É importante, no entanto, ressaltar que o orçamento descentralizado pode resultar em uma falta de padronização nos projetos (Votorantim p.9). Isso que dizer, uma iniciativa aplicada em uma localidade pode tem um resultado diferentes e for aplicada em outra localidade. Por isso, é importante que a Fundação Siemens e as rede locais, responsáveis pelos treinamentos e capacitações, mantenham os mesmos padrões em todo território

\subsection{Projetos}

Foi visto que a gestão do projeto pode ser responsabilidade do colaborador ou do departamento que o propôs, como propõe o Instituto Votorantim (p.32)

Quando a iniciativa é centralizada e proposta por algum departamento, a decisão é tomada internamente por aqueles que possuem uma visão mais holística da empresa. Neste caso a tendência é ser mais consistente e integrada com os objetivos da organização. No entanto, os funcionários podem não se identificar com essa ação e não abraçarem a causa. 
Quando a iniciativa parte de um colaborador, o engajamento dele tende a ser maior. Geralmente, nesse caso, o colaborador oferece uma perspectiva mais assertiva da causa, por estar mais ciente de seu contexto, baseado em suas vivências e experiências. Contudo, é preciso avaliar se os interesses pessoais do colaborador estão alinhados com as diretrizes do programa e se o projeto possui alguma estrutura definida ou se já existe um grupo de voluntários formado.

A Points of Lights Foundation, organização não governamental, afirma que "o mais valioso investimento que uma empresa pode fazer é desenvolver um programa de voluntariado empresarial que se alinhe de maneira estratégica com a atividade principal da companhia, e contribua para sua razão de ser”.

De acordo com o que foi apresentado no final da etapa do diagnóstico, podemos constatar o impacto atingindo pelos departamentos que desenvolveram projetos. Observamos que tiveram êxito em colocar em consonância seus objetivos próprios com as estratégias da empresa.

A área de recursos humanos da Siemens encontrou uma ótima forma de capacitar e desenvolver certas habilidades em seus estagiários. O Social Responsability dá autonomia aos voluntários para elaborarem seus próprios projetos dentro do departamento. Elaborando projetos sociais nas comunidades locais, os estagiários desenvolvem liderança e pensamento estratégico, e maior sinergia para trabalhar em grupo.

O Social Finance é uma iniciativa anual de algumas áreas financeiras da Siemens, cujo intuito é ajudar determinada instituição de ensino; é uma ação que foge do escopo do departamento mas se mantém alinhada as diretrizes da Siemens.

Há, também, a parceria da Fundação Siemens com a área de Cidadania Corporativa, que mostra todo o potencial dessa união na Escola Formare Siemens e o projeto Multiplicadores de Inteligência Emocional. Ao lecionarem aulas 
nesses dois projetos os colaboradores desenvolvem habilidades de comunicação, didática e capacidade de lidar com diferenças.

Com os projetos acima citados, podemos constatar que há inúmeros benefícios se os objetivos da empresa e do departamento forem estratégicos e alinhados. Constatamos também que, em relação a ceder as horas, cabe ao gestor ter um olhar apurado e crítico para avaliar se o trabalho voluntariado está desenvolvendo seu funcionário. Se ele está perdendo em quantidade de horas trabalhadas, mas está investindo em qualificação profissional.

Outro ponto a se ressaltar refere-se a necessidade da empresa estabelecer uma política de reconhecimento, pois a falta dela dificulta o trabalho das redes locais em mobilizar e engajar o maior numero de colaboradores. O reconhecimento leva departamentos e colaboradores a terem maior empenho em propor novos projetos. Acreditamos que baixa adesão de colaboradores em algumas regiões se deva a falta desta política. Tendo isso em vista, indicamos que a adoção dessas práticas para a melhora do desempenho da empresa.

\subsection{Voluntários}

O voluntariado é uma ação vantajosa para a sociedade como também gratificante para quem a realiza. Os colaboradores voluntários constituem o ativo fundamental das ações, pois ao se alinharem à causa cedem tanto o seu tempo quanto suas competências em apoio à ela. $\mathrm{O}$ voluntário traz uma contribuição significante tanto nos aspectos econômicos como nos sociais. Uma das estratégias usadas pela Siemens em seu modelo de projeto era a motivação de seus voluntários

No entanto, quais seriam as vantagens que levam alguém a se tornar em um colaborador voluntário?

E de acordo com GOLDBERG (2000, p.23), programas de voluntariado empresarial ajudam há desenvolver de habilidades pessoais e profissionais, promovem a lealdade e a satisfação com o trabalho, além de atrair e reter funcionários qualificados. 
É possível afirmar que há um desenvolvimento maior na inteligência emocional daquele que pratica a atividade, sem contar que o indivíduo expande o círculo afetivo, e tem possibilidade de descobrir novos potenciais e ampliar os seus paradigmas. É possível fazer essa antologia baseada na teoria de hierarquia das necessidades de Maslow (2000, p.105). O trabalho voluntario cria meios de satisfazer as necessidades sociais, de estima e realização.

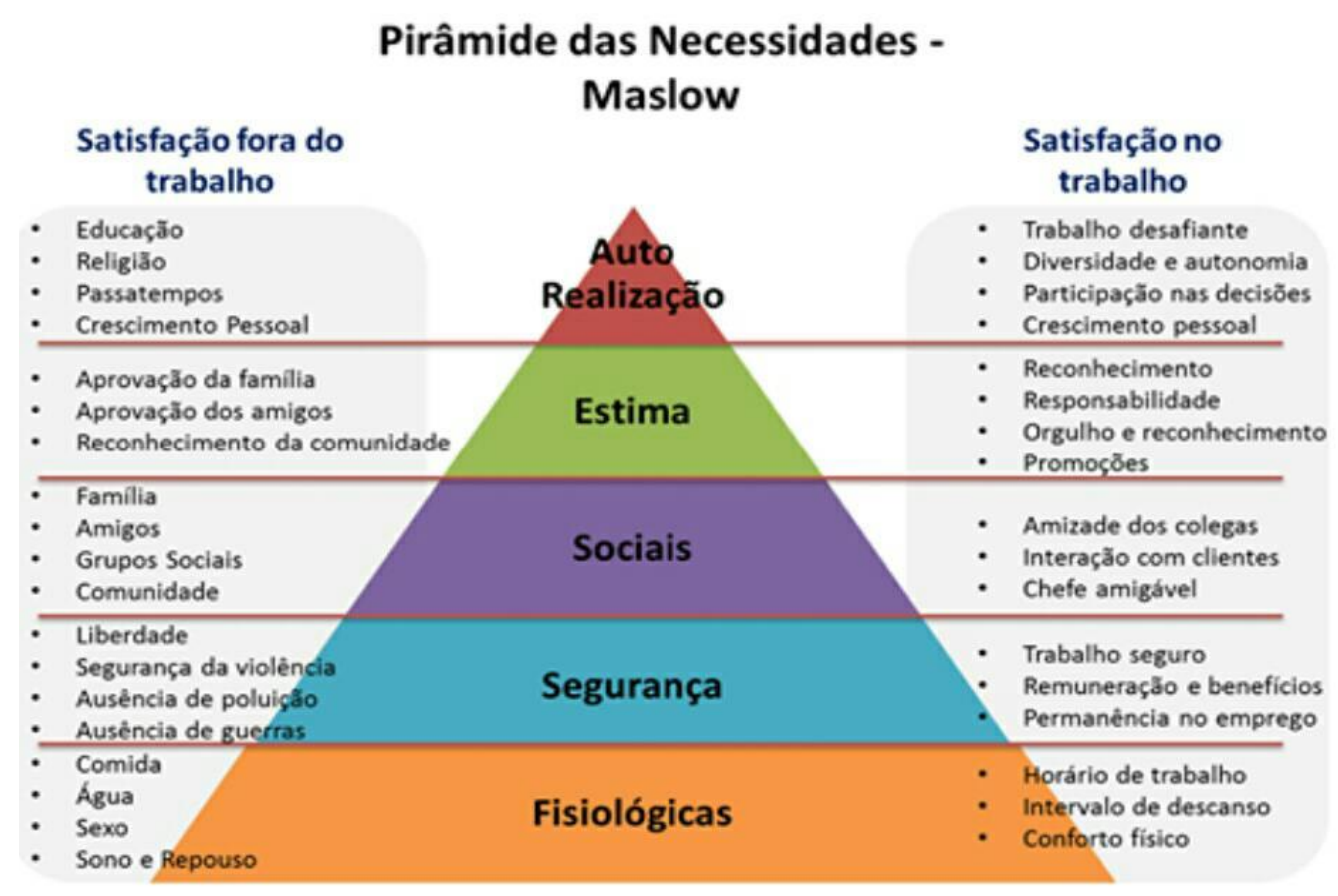

Figura 4 Pirâmide das Necessidades Humanas Básicas Fonte: MASLOW, 2000, p. 105

A partir da pirâmide, vimos que o programa da Siemens consegue mesclar necessidades tanto do trabalho em si quanto as de fora dele. Isso porque é possível que os colaboradores ao usarem o seu know how profissional em prol da sociedade se sintam mais envolvidos com a iniciativa, gerando um auto orgulho de participarem de uma organização que não só auxilia outras pessoas, mas os estimula a continuar na prática de boas ações por meio do voluntariado, e a se sentirem dignos por participar de projetos transformadores da sociedade. A meta definida em 2012, em que $10 \%$ dos colaboradores estariam envolvidos nas 
atividades voluntárias foi atingida em 2016 de acordo com seu relatório de sustentabilidade.

O entrevistado, no entanto, relatou o receio de funcionários se envolverem nas atividades de voluntariado durante o expediente, em função do medo do seu trabalho ser julgado menos produtivo pelos gestores.

acordo com o Censo CBVE (2016, p.13), apenas 25\% das organizações promovem as ações voluntárias durante o horário de trabalho. Para funcionar dessa forma, é interessante determinar critérios de produtividade no departamento para que a pressão do gestor direto não afete o engajamento dos colaboradores no programa. As atividades devem ter também a possibilidade de serem mistas, ocorrendo no expediente e nos finais de semana com a possibilidade de mobilizar amigos e as família. Assim reduziria este tipo de conflito e haveria maior flexibilidade e harmonia entre colaboradores e gestores

\subsection{Instituição Siemens e parceiras}

Ao longo desse artigo apontamos que umas das estratégias do programa de voluntariado éa parceria da empresa com a Fundação Siemens, uma vez que está contribui com sua técnica e experiência na gestão e no suporte de projetos, além de fornecer a capacitação e treinamentos necessários aos voluntários.

E não é apenas a Siemens que faz uso dessa estratégia. Nota-se pela pesquisa BISC (2016, p.45) que muitas empresas creditam o sucesso de seus investimentos sociais as parcerias com organizações sem fins lucrativos.

As vezes é necessário uma ajuda externa para ser dar os primeiros passos no processo. Segundo o Censo GIFE 2014 (p.45), 63\% das empresas precisam do auxilio das instituições e fundações para implantar o programa de voluntariado e desenvolver ações sociais.

A parceria abrange talento e habilidades, respeitando a especificidade de cada empresa, ,significa dizer que as organizações se complementam com recursos e compartilham riscos, em um propósito comum as partes. Diferentemente de uma aliança estratégica, que se baseia na igualdade de competência, onde ambas empresas poderiam atuar de forma independente mas 
resolveram unir suas forças em ações que podem gerar vantagem competitiva (Noleto, 2000).

O vínculo realizado com o grupo Fleury se enquadrou como uma aliança estratégica onde foram somadas as competências, a dos médicos do grupo com a da Siemens em desenvolver equipamentos hospitalares. São empresas de setores diferentes mas com valores e interesses em comum frente a mesma causa, que optaram por ter o mesmo posicionamento estratégico.

Ocaso da Escola Formare Siemens se enquadra como uma parceria e não aliança. A Fundação Siemens ficou encarregada da parte de gestão e de entrar com recursos financeiros, já a Siemens com seus colaboradores voluntários que ministram as aulas, e a Fundação Iochpe deu suporte quanto parte metodológica e didáticas da Escola.

Assim constatamos que a Siemens conseguiu identificar instituições com propósitos e valores semelhantes, e a partir daí procurou se correlacionar de forma construtiva, definido os objetivos e o papel de cada parte nas parceria e alianças estratégicas formadas. O resultado final mostra como foi possível agregar valor para todos os envolvidos no processo.

\subsection{Comunicação}

"Definir a melhor forma de divulgar o trabalho voluntariado empresarial é crucial para as ações propostas . Essa dependerá dos modelos de operacionalização escolhidos pela empresa e das escolhas estratégicas feitas." ( Instituto Votorantim 2014, p.44)

Uma vez que o diálogo entre todos os elementos envolvidos no processo pode por um lado impulsionar o programa e torná-lo possível, por outro lado uma falha de comunicação pode dificultar e inviabilizá-lo. Observamos que relatório de sustentabilidade da Siemens e sua plataforma online funcionam como ferramentas de engajamento de stakeholders.

A plataforma online abriu a possibilidade de maior integração entre os voluntários, o que propicia trocas e compartilhamento de ideias diferentes, 
abrindo espaço para debates e levantando questões relevantes entre as partes em comum, novas ideias aparecem e o aprendizado é enriquecedor. Além de permitir aos colaboradores terem informações sobre o impacto das ações através de números de beneficiados, de voluntários, horas de planejamento e de execução.

Embora o portal abra todas essas oportunidades e a Siemens tenha atingido sua meta de $10 \%$ de colaboradores voluntários, ainda há aquela diferença de engajamento entre as unidades regionais.

$\mathrm{Na}$ entrevista com Ramon, ele atestou que nunca foi realiza uma pesquisa interna com os colaboradores para saber a opinião deles sobre do programa. A nosso ver isso é uma falha de diálogo entre empresa e colaboradores, pois a comunicação é apenas unilateral. De acordo com os Instituto Ethos :

"A experiência brasileira e internacional mostra, porém, que mais cedo ou mais tarde as empresas tendem a fazer uso de algum tipo de levantamento sobre as expectativas e preferências de seus funcionários" (Goldberg 2011, p.59)

O mais adequado é que a empresa realize uma pesquisa para sondar as considerações dos colaboradores sobre o programa de voluntariado. Tal procedimento seria uma forma de identificar as lacunas do processo, e apontar por que certas regiões possuem mais voluntários do que outras. A partir dos resultados traçar uma estratégia para diminuir as diferenças entre localidades.

Em relação a comunicação com o público externo vimos que o relatório sustentável foi o meio que a organização encontrou para demonstrar a transparência de suas ações. A divulgação de suas práticas de cidadania corporativa contribui para se formar uma imagem da marca como uma empresa comprometida com as questões socais. A partir do gráfico da pesquisa BISC (2016 p. 62) podemos supor que ter seu próprio relatório sustentável será padrão para empresas que praticam o voluntariado. Observamos um crescimento expressivo de empresas que adotam essa prática. Em 2010 havia 65\%, em cinco anos o índice aumentou para $94 \%$. 


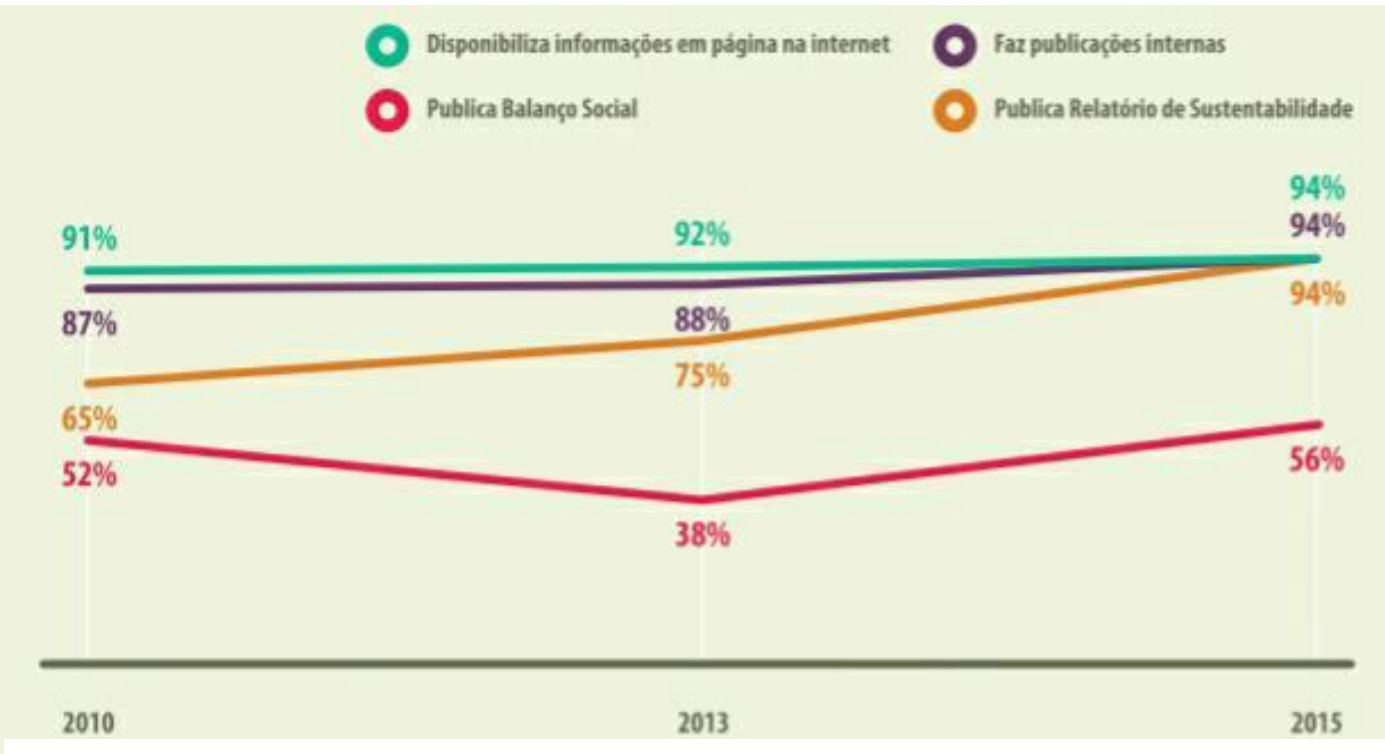

Figura 5 Meios de divulgação de atuação social

\subsection{Reconhecimento}

Foi visto que políticas de reconhecimento e valorização são importantes para manutenção do programa. No voluntariado, pelo seu caráter facultativo, é primordial saber reconhecer quem cooperou para o êxito dos projetos com ações concretas. De acordo com o Instituto Ethos ( p.73):

"Parte do sucesso da política de valorização e reconhecimento é descobrir qual a maneira mais adequada de homenagear seus voluntários, sobretudo aqueles que realmente se destacaram, sem diminuir o trabalho dos outros. Afinal, as políticas de reconhecimento e valorização devem servir como emulação e não como instrumento de competição."

Contudo a prática de reconhecimento ainda não ocorre de maneira geral. De acordo com a pesquisa perfil do voluntariado 3,60\% das empresas brasileiras não possuem política de reconhecimento definida. 
Na política de reconhecimento proposta pela Siemens vimos que há o sistema de pontos. Faz parte do programa interno de incentivo, a troca de pontos por brindes que apresentam um valor mais simbólico. É importante evitar brindes com valores expressivos para não atrair funcionários que não estão comprometidas com os propósitos reais que é o de contribuir socialmente.

Outra forma de reconhecimento se dá através da plataforma online, que é o meio mais usual utilizado pela Siemens para informar internamente sobre o trabalho voluntário. É uma maneira de engajar e fidelizar seus funcionários com o projeto, e ao mesmo tempo valorizar aqueles que abraçam as causas sociais. Na plataforma há selos de reconhecimento, fotos das atividades e notícias com os resultados das ações.

Mas vimos que falta uma política interna valorizando de forma mais pessoal o voluntário, isto é que ressalte suas competências particulares. A valorização como ocorre atualmente se dá de maneira coletiva, e não sob o aspecto individual de cada voluntário. Uma proposta para aumentar o incentivo individual seria oferecer certificados para os voluntários em cada treinamento e capacitação. A Siemens enquanto empresa recebe certificados e prêmios de outras instituições reconhecendo seu trabalho, da mesma maneira os voluntários poderiam receber certificações sobre as competências adquiridas. 


\section{Conclusões e contribuições do estudo}

O presente estudo focou no caso específico da Siemens Brasil, mas salientamos que o processo de implantação do programa de voluntariado deve ser elaborado de acordo com as particularidades de cada empresa. Não existe modelo único, as etapas que foram descritas servem apenas como referência e levanta pontos importantes a serem considerados. A direção a ser seguida vai depender dos objetivos da organização com o programa voluntariado e de quais estratégias serão traçadas para alcançá-los.

O objetivo da Siemens é ser reconhecida como exemplo de cidadania corporativa no Brasil. E para isso se concretizar planejou sua estratégia com base na parcerias formadas com outras instituições; no suporte da Fundação Siemens e das rede locais; no engajamento de colaboradores e departamentos para criar e gerir seus próprios projetos ,que foi possível devido ao modelo de financiamento adotado.

Nesse modelo cada departamento define seu próprio orçamento em investimentos sociais de acordo com seus objetivos específicos. No entanto, as atividades a serem elaboradas precisam estar relacionadas aos temas determinados pela organização e que apresentam maior impacto em seus stakeholders. A Siemens tem como fundamento apenas dois temas: Tecnologias básicas, aquelas que proporcionam melhores condições de vida, e educação, sendo esta o foco principal da organização.

Os voluntários ensinam conhecimento, mas ao mesmo tempo estão sujeitos a um aprendizado constante. Há uma dinâmica, onde o ensino e o aprendizado de valores são elementos nos programas de educação. Ensinar e aprender são lados da mesma moeda. Os projetos que alinham habilidades e competências do campo de atuação dos colaboradores promovem sua capacitação profissional e os 
motivam, visto que os voluntários usam seu know-how em prol de uma causa nobre.

Para o andamento do programa foi preciso estabelecer uma boa linha de comunicação. Devido a Siemens estar em diferentes regiões geográficas no Brasil, as redes locais e o portal online foram indispensáveis para a sinergia e para o acompanhamento dos resultados dos projetos, e também no fomento das ações sociais.

A parceria com a Fundação Siemens foi determinante para a empresa Siemens colocar em prática uma política de voluntariado. A Fundação colaborou desde o processo de implantação até na gestão de alguns projetos. Ela ainda hoje oferece todo suporte técnico a atividades desenvolvidas pelo programa, incluindo treinamento e capacitações. Observamos nesse trabalho que criar vínculo com fundações e instituições é uma estratégia muito utilizada por outras empresas, que creditam o êxito de seus programas a formação de tais parcerias.

Dentro deste trabalho vimos também a formação de uma aliança estratégica da Siemens como grupo Fleury, que a partir de posicionamentos semelhantes, puderam identificara oportunidade de criarem valor e vantagem competitiva, ao mesmo tempo que estavam atuando em projetos sociais.

Todas essas estratégias fizeram a Siemens conquistar seu objetivo de ser referência em cidadania corporativa. Em 2014, destacou-se no categoria "Ética e Relacionamento com Stakeholder" na premiação promovida pela revista Gesta \& $\mathrm{RH}$, em que reconhece as 100 melhores em cidadania corporativa. No ano de 2015, foi eleita a empresa mais sustentável pelo Guia Exame de Sustentabilidade; reconhecida com o selo Pró-Ética pela controladoria geral da União; e ganhou o prêmio LIDE de educação ,organizado pelo Grupo de líderes Empresarial de acordo com os relatórios sustentáveis de 2014 e 2015.

Como foi ressaltado há uma série de pontos positivos no programa de voluntariado, mas é preciso contrapor alguns aspectos que necessitam ser melhorados. Na nossa pesquisa sugerimos a reflexão sobre alguns tópicos:

- Necessidade de instituir uma política de reconhecimento individual com base nas certificações das capacitações realizadas pelos voluntários.

- Propor a existência de um horário misto, que inclua horas dentro e fora do expediente para as atividades de voluntariado social. 
- Criar índices de produtividade de modo que os gestores possam avaliar como o trabalho voluntário está impactando na performance do colaborador.

- Instituir pesquisas de opinião que sondem como os voluntários se sentem em relação ao programa, isto significa estabelecer um diálogo mais efetivo com os colaboradores.

- Propor reuniões periódicas entre as redes locais, de maneira que cada grupo possa expor resultados, identificar as diferenças de mobilização e traçar estratégias

Os resultados da Siemens são referência em cidadania corporativa. A organização encontrou uma forma de se fortalecer a partir da transferência de conhecimento entre todos os envolvidos no processo. A empresa não apenas agregou valor a si, mas o compartilhou.

Concluímos que a Siemens faz parte de uma nova geração de empresas que aplicam os princípios de valor compartilhado como forma de garantir sua longevidade. De acordo com Porter e Kramer, podemos definir valor compartilhado como:

"O conceito de valor compartilhado redefine as fronteiras do capitalismo. Ao conectar melhor o sucesso da empresa com o progresso da sociedade, abre muitas maneiras de atender a novas necessidades, ganhar eficiência, criar diferenciação e expandir mercados."

Essa nova linha de pensamento econômico erradica a dissociação entre a empresa fazer investimentos sociais e investir em si mesma, ambas ações estão correlacionadas diretamente. Se empresas aderissem à essa nova mentalidade, os custos em responsabilidade social se transformariam em lucro sustentável. Isso só será possível a partir de um novo modelo de gestão. Estudos futuros poderiam se aprofundar nesse modelo e também analisar a correlação entre empresas e fundações, isto é, como que instituiçõoes sem fins lucrativos formam parcerias com empresas em programas de voluntariado. 


\section{Referências}

BISC - Comunitas. Benchmarking do Investimento Social Corporativo

Disponível em: http://www.bisc.org.br. Acesso em 05 de Abril de 2017.

CARROLL, Archie B. Corporate Social Social Responsabilities of Business

Corporation Report. Business and Society, v. 38, p 282, 1999.

CENSO GIFE /2014. São Paulo:2015

CENSO CBVE/ 2016. Rio de Janeiro.2016

COSTA,P. Responsabilidade social empresarial. Conselho Federal de Administração. São Paulo,25, Mar. 2014. Disponível em:http://www.cfa.org.br/acoes-cfa/artigos/usuarios/responsabilidade-social-

empresarial. Acesso em : 26 de maio de 2017

CORULLÓN, Mônica Beatriz Galiano e MEDEIROS Filho, Barnabé. Voluntariado na empresa: gestão eficiente da participação cidadã. São Paulo, Peirópolis, 2002.

COUTINHO, Renata Buarque Goulart; TOMEI, Patrícia Amélia. Responsabilidade social corporativa e cidadania empresarial: Uma análise conceianópolis. 2000. ANPAD

ESTRATÉGIAS de Empresas no Brasil: atuação social e voluntariado. São Paulo, Programa Voluntários do Conselho da Comunidade Solidária, 1999.

ENGEL, W. Voluntariado empresarial: Do conceito à prática. Rio de janeiro: Sob Medida, 2013.

Fundação Iopech. Tornamos melhores profissionais e cidadãos, dia a diretora da Siemens. São Paulo, 2013. Disponível em http://w3.siemens.com.br/home/br/pt/cc/sobre-a-siemens/pages/valores-visao-emissao.aspx?istablet=true. Acesso em 06 de junho de 2017

Guia de voluntariado empresarial: Orientações para o desenvolvimento de programas de voluntariado nas empresas do grupo Votorantim. São Paulo: Grupo Votorantim, 2014.

GOLDBERG, Ruth. Como as empresas podem implementar programas de voluntariado. São Paulo, Instituto Ethos, 2001. 
Marcela, Marchi. O poder do reconhecimento empresarial. Disponível em http://www.filantropia.ong/informacao/8733-o-poder-do-reconhecimento-para-ovoluntariado-empresarial. Acesso em 01 de junho de 2017.

NOLETO, M. J. Parcerias e alianças estratégicas: uma abordagem prática. São Paulo: Global, 2000. 47 p.

NUNES,C. Voluntariado empresarial como ferramenta de valorização institucional . Rio de janeiro,2012. Monografia ( Pós-graduação em Administração ) - Departamento de economia e gestão da sustentabilidade. Universidade Federal do Rio de Janeiro.

PORTER,M.E;Kramer, M.R. Criação de Valor compartilhado. Havard Business Review Brasil, São Paulo, Janeiro, 2011. Disponível em; <http://hbrbr.uol.com.br/criacao-de-valor-compartilhado/> . Acesso em:27 de maio de 2017.

Siemens Ltda. Corporate Communications. Relatório de Sustentabilidade 2014. São Paulo. 2015. Disponível em $:<$ http://www.siemens.com.br/relatorioanual2014/>. Acesso em :15 de abril de 2017.

Siemens Ltda. Corporate Communications. Relatório de Sustentabilidade 2015. São Paulo,2016. disponível em:<http://siemens.com.brr/relatorioanual2015/>. Acesso em:15 de abril de 2017

The points of Light Foudation Corporate volunteer programs - a strategicresource for business: basic guide lines and considerations for start up and strengthening of corporate volunteering in Brasil. Washington, s.d. $12 \mathrm{p}$ 